\title{
INDICADORES RELEVANTES PARA O SUCESSO DO COMPARTILHAMENTO DO CONHECIMENTO TÁCITO NAS EMPRESAS: Evidências empírico-exploratórias em PME's catarinenses
}

\section{INDICATORS RELEVANT TO THE SUCCESS OF SHARING KNOWLEDGE ON BUSINESS TACIT: Exploratory empirical evidence on SMEs catarinenses}

\author{
Emílio Da Silva Neto ${ }^{1}$; Inara Antunes Vieira Willerding ${ }^{2}$; Neri dos Santos ${ }^{3}$; Édis Mafra Lapolli ${ }^{4}$ \\ ${ }^{1}$ Universidade Federal de Santa Catarina - Florianópolis - Santa Catarina - Brasil \\ emilio@arcoirisalimentos.com.br \\ ${ }^{2}$ Universidade Federal de Santa Catarina - Florianópolis - Santa Catarina - Brasil \\ inara.antunes@gmail.com \\ ${ }^{3}$ Centro Universitário Internacional - Curitiba - Paraná - Brasil \\ neri.s@uninter.com \\ ${ }^{4}$ Universidade Federal de Santa Catarina - Florianópolis - Santa Catarina - Brasil \\ edispandion@gmail.com
}

\begin{abstract}
Resumo
As pequenas e médias empresas brasileiras, inseridas num mercado altamente competitivo, enfrentando concorrentes de todos os portes e nacionalidades, precisam estar sempre atentas às características intrínsecas dos segmentos em que atuam, de forma a sustentar ou ampliar as suas vantagens competitivas [NORTH, DA SILVA NETO, DÁVILA CALLE, 2013]. Para isso, entre tantas outras competências, o empresário precisa agir com muita visão, velocidade, flexibilidade e percepção na gestão de seu capital intelectual, visando superar os desafios da nova sociedade conhecimento, caracterizada por mudanças rápidas e radicais. Nesse sentido, o presente artigo apresenta algumas formas de interação social em pequenas e médias empresas que, por meio de estímulos, motivação e incentivos, potencializam o compartilhamento e a reutilização de conhecimentos tácitos, fazendo com que a maioria dos funcionários se sintam reconhecidos e úteis à empresa. Um estudo de caso foi realizado em 09 pequenas e médias indústrias de Jaraguá do Sul, no Estado de Santa Catarina, município de economia pujante e com uma das maiores taxas de sobrevivência de empresas no âmbito nacional, onde foi evidenciado indicadores relevantes para o sucesso do compartilhamento do conhecimento tácito em empresas deste porte.
\end{abstract}

Palavras-chave: gestão do conhecimento; conhecimento tácito; PME’s.

\section{Introdução}

Os fatores clássicos de produção terra, capital e trabalho eram a base das organizações para gerarem vantagens competitivas no mercado. Hoje, esses fatores não possuem mais tal efetividade, 
pois um novo mercado se faz presente, em que visa um novo fator de produção, com novas bases em prol de vantagens competitivas, o conhecimento.

Tendo as organizações assumido essa nova arquitetura, em que o uso do conhecimento reflete em sua potencialidade, tanto social, quanto econômica, elas serão capazes de conquistar e consolidar sua participação nessa nova economia que se desenha, um mercado globalizado, tendo o conhecimento um papel de destaque, no que se refere à construção e armazenamento do conhecimento por meio da informação ampliada.

A construção de um Brasil mais produtivo é condição sine qua non para o País avançar. Assim, cabe às empresas o fortalecimento e a inovação de suas competências, com um crescimento qualitativo e quantitativo, em forma de elevação da produtividade, agregação de valor e inovação.

Com a globalização, as empresas só se manterão competitivas, de forma sustentável, se levarem em consideração o fator de produção "conhecimento", de maneira efetiva. De fato, somente com a criação de novos conhecimentos é que as empresas terão a possibilidade de inovar e de enfrentar a concorrência, encarando a customização intensa e os ciclos de vida de produto cada vez mais curtos, a saturação ou o desaparecimento de mercados, bem como o surgimento de novos.

Para vencer neste ambiente, em situação de constante turbulência, se faz necessário movimentar dinamicamente todos os recursos de conhecimento da empresa em busca de maior competitividade, diferenciação e, inovação (NORTH, DA SILVA NETO, DÁVILA CALLE, 2013).

É importante ressaltar que não importa o tamanho ou segmento de uma empresa, ela precisa de uma adequada gestão do conhecimento, especialmente daquele ainda implícito (tácito) - de posse individual de seus empregados, não explicitado e não compartilhado com a toda a equipe para que todos da empresa possam fazer uso dele para um trabalho mais efetivo e produtivo. $\mathrm{O}$ conhecimento organizacional é, atualmente, o principal fator de produção, de agregação de valor, de produtividade e de crescimento das empresas (REVISTA EMPREENDEDOR, 2013).

A principal fonte de riqueza para as empresas é seu capital intelectual, ou seja, as pessoas que fazem parte das companhias. Drucker (2001), considerado o pai da administração moderna, afirma que no passado as fontes de vantagem competitiva eram o trabalho e os recursos naturais. Agora e neste século, a chave para construir a riqueza das nações é o conhecimento.

Este artigo tem como foco as pequenas e médias empresas (PME's) brasileiras, espinha dorsal do crescimento econômico do País, representando cerca de $100 \%$ do total de empresas, empregando cerca de dois a cada três trabalhadores e respondendo por $20 \%$ do Produto Interno Bruto (PIB) brasileiro, mas que tem uma baixa produtividade: em torno de $40 \%$ da produtividade vista na faixa das grandes empresas (SEBRAE, 2013). 
Segundo o Sebrae de Santa Catarina (2013) o estado catarinense "abriga um pujante parque industrial, considerado o quarto maior do Brasil. Indústrias de grande porte e milhares de pequenas empresas fazem deste estado a oitava maior economia brasileira pelo tamanho de seu PIB."

A cidade de Jaraguá do Sul se destaca por apresentar a maior taxa de sobrevivência de empresas (com dois anos de atividade) em Santa Catarina, com uma taxa de 83\%, ficando à frente de Blumenau (80\%), Joinville (76\%), Itajaí (72\%) e Florianópolis (70\%) e, considerando uma taxa média de sobrevivência nacional de $75,6 \%$, está na $19^{\mathrm{a}}$ posição entre todos os 5.561 municípios brasileiros (SEBRAE, 2013), o que explicita uma capacidade superior das pequenas e médias empresas jaraguaenses em superar as dificuldades nos primeiros anos do negócio e contribuir para o desenvolvimento econômico e social. Mesmo em comparação com os percentuais de vários países europeus, Jaraguá do Sul tem uma taxa expressiva, a saber: Áustria com 79,6\%, Espanha com 69,8\%, Itália com 67,9\% e Holanda com 49,7\% (OECD, 2013).

Este bom índice de sobrevivência das empresas de Jaraguá do Sul parece estar relacionado aos requisitos de capital, conhecimento e tecnologia que tendem a ser proporcionalmente, maiores no segmento industrial, vocação principal do município, o que reduz a entrada de concorrentes e a pressão concorrencial.

Diante desse contexto, esse artigo busca evidências empírico-exploratórias em PME's situadas em Jaraguá do Sul, indicadores para a socialização e compartilhamento do conhecimento tácito em prol de destaque no mercado atuante.

\section{Gestão do Conhecimento}

Adam Smith, no capítulo X do livro "A Riqueza das Nações”, obra de 1776 que funciona como uma espécie de marco zero para o entendimento do capitalismo, sustenta que a busca do lucro por meio da iniciativa individual é a mais possante força de transformação ao alcance dos seres humanos; é dela que vêm, no fim das contas, a criação das riquezas e, como resultado de sua inevitável distribuição, o progresso, a libertação das pessoas e o avanço do bem estar comum. Adam Smith passou para a história como o primeiro pensador a perceber o caráter revolucionário da iniciativa privada.

Assim, cabe às empresas privadas o fortalecimento e inovação de suas competências, com um crescimento qualitativo e quantitativo em forma de elevação da produtividade, agregação de valor e inovação.

A nova sociedade do conhecimento é caracterizada por mudanças, dentre as quais, uma das mais impactantes é a alteração do foco do trabalho (antes mão de obra e hoje cérebro de obra), na 
medida que o maior insumo é o conhecimento, traduzido como a capacidade de absorver, gerar e disseminar melhorias, soluções, ideias e inovações.

Conhecimento e gestão do conhecimento, ambos são de complexa definição. Alguns definem conhecimento como um derivado de informação, a qual, por sua vez, é proveniente de dados. Assim, conhecimento é um conjunto de dados ou informações, organizados e contextualizados de maneira que sejam úteis para uma organização. A ideia central é que os esforços de gestão do conhecimento devam ser para criar, codificar e compartilhar conhecimentos valiosos para a organização, algo importante também para as pequenas e médias empresas, já que a onda da era do conhecimento afeta igualmente todas as organizações (APO, 2009).

Para uma melhor elucidação, se faz necessário desenvolver algumas ideias e definições sobre a principal fonte de riqueza de uma empresa, o conhecimento, proveniente do seu capital intelectual e humano. Segundo Stewart (1998, p. 13),

Capital intelectual é a soma dos conhecimentos de todos em uma empresa o que lhe proporciona vantagem competitiva. Ao contrário dos ativos, com os quais empresários e contadores estão familiarizados - propriedade, fábrica, equipamentos, dinheiro constituem a matéria intelectual: conhecimento, informação, propriedade intelectual, experiência, que pode ser utilizada para gerar riqueza.

O capital intelectual possui como característica a intangibilidade, reflexo do conhecimento das práticas de trabalho individuais. Nahapiet e Ghoshal (1998) abordam que

O capital intelectual de uma organização não é propriedade particular de um indivíduo, mas resulta e desenvolve-se nas relações que permeiam a estrutura e os processos de troca, sendo moldado de acordo com a evolução dessas relações ao longo do tempo. É, portanto, de difícil imitação e raro, pois é característico de cada organização; deve ser valioso, gerando produtos capazes de proporcionar atratividade durável ao cliente, superior à da concorrência.

Nonaka e Takeuchi (2004, p. 25), conceituam conhecimento como "a capacidade que uma empresa tem de criar conhecimento, disseminá-lo na organização e incorporá-lo a produtos, serviços e sistemas". Os autores ainda enfatizam que se refere a um processo dinâmico realizado por pessoas na qual a ação é enfatizada.

Os autores Takeuchi e Nonaka (2008) definem dois tipos de conhecimento: tácito e explícito que, quando interagem entre si, produzem conhecimento organizacional. Polanyi (1966, p. 4) um dos primeiros estudiosos a conceituar conhecimento tácito, afirma que "nós sabemos mais do que podemos expressar verbalmente", isto é, o indivíduo sabe mais do que consegue exprimir em palavras ou por meio da escrita. Pode-se afirmar que o conhecimento tácito é algo pessoal, adquirido pela experiência, pela prática, uma habilidade e que nem sempre se manifesta exteriormente, a qual é baseada, em parte, na própria experiência e aprendizado, sendo assim, de cunho pessoal e de difícil formalização e comunicação. 
Takeuchi e Nonaka (2008), no que se refere ao conhecimento explícito, definem como sendo de fácil comunicação e acesso, é adquirida por meio de documentos, linguagem formalizada, podendo citar como exemplo, manuais, relatórios, dentre diversos outros formatos explicitados.

Os autores O’Dell e Grayson (1998) ponderam que têm muito conhecimento a ser descortinado nas empresas, especialmente com relação a conhecimento tácito na forma de knowhow e melhores práticas. Esse conhecimento pode ser observado no dia a dia do indivíduo na organização por suas práticas, habilidades, feeling ou intuições nas atividades que exerce.

Os autores Takeuchi e Nonaka (2008) consideram que a interação entre o conhecimento tácito (pessoal) com o explícito, gera um processo social entre indivíduos, pois o conhecimento humano é criado e expandido, não ficando assim, configurado em um único indivíduo. Para tal dinâmica, os autores determinam quatro estágios de conversão do conhecimento: socialização, externalização, combinação e internalização.

Gerir conhecimento passou a ser uma ferramenta de extrema importância para as empresas e, assim, os conhecimentos tácitos, que se encontram na mente de seus colaboradores, também precisam ser geridos e, se possível, resgatados e disseminados.

Gerir conhecimento não é tarefa fácil. Mesmo com um ambiente apropriado, as empresas precisam despertar em seus colaboradores a sua importância, bem como, a importância de seus conhecimentos para a organização. Alguns autores, portanto, afirmam que pode-se identificar alguns indicadores importantes para a disseminação e compartilhamento do conhecimento tácito nas organizações.

\section{Indicadores da disseminação e compartilhamento do Conhecimento Tácito}

O conhecimento tácito refere-se a processos desenvolvidos intrinsecamente, isto é, por experiência, vivências, reflexões, internalizações e talentos individuais, inerentes ao ser humano, sendo esses determinantes para a disseminação e compartilhamento do conhecimento tácito.

Uma boa parte das competências individuais está sob a forma de conhecimento tácito. Com origem no latim, de tacitare, que se refere a algo que é muito difícil de articular, de colocar em palavras ou imagens, normalmente é um conhecimento altamente internalizado que possibilita saber fazer algo ou reconhecer uma situação análoga.

Segundo Dos Santos (2012), o conhecimento tácito é procedural, pessoal, específico de um determinado contexto, difícil de ser formulado e comunicado, e envolve modelos mentais que estabelecem e manipulam analogias. Seus elementos técnicos podem ser exemplificados como know how concreto, técnicas e habilidades que permitem ao indivíduo o saber fazer e dirigi-lo à ação. O conhecimento tácito é fortemente incorporado pela experiência de um indivíduo e não passa 
pela formalização com palavras. Está-se, de fato, num estágio de sublinguagem do reflexo, dos automatismos, do instinto ou de um conhecimento prático que se materializa pelo gesto. A transmissão deste tipo de conhecimento se dá pela socialização, isto é, pela interação física, observação ou imitação. Trata-se de tutoria ou companheirismo, nos meios profissionais, ou de aprendizagem ou treinamento, nos meios artesanais ou esportivos.

Já o conhecimento explícito, também segundo Dos Santos (2012), passa, como o seu nome indica, pela mediação da linguagem. É um conhecimento que permite a um indivíduo a aquisição do saber (entender e compreender) sobre determinados fatos e eventos, mas não lhe permite agir.

Porém, como o indivíduo exerce suas práticas e interage dentro da empresa, essas também podem agir como facilitadores à disseminação e compartilhamento do conhecimento tácito. Lemos (2008) elaborou um modelo heurístico para a transferência de conhecimento tácito em uma empresa. O termo heurístico, segundo Japiassú e Marcondes (2006, p. 131) se origina da palavra grega heuriskein, "que se refere à descoberta e serve de ideia diretriz numa pesquisa".

Lemos (2008), em seu modelo heurístico, subdivide as formas de se transferir conhecimento em quatro indicadores: cultura organizacional, estratégia de transferência do conhecimento, fatores idiossincráticos e estrutura organizacional, conforme mostra a figura 03 , a seguir.

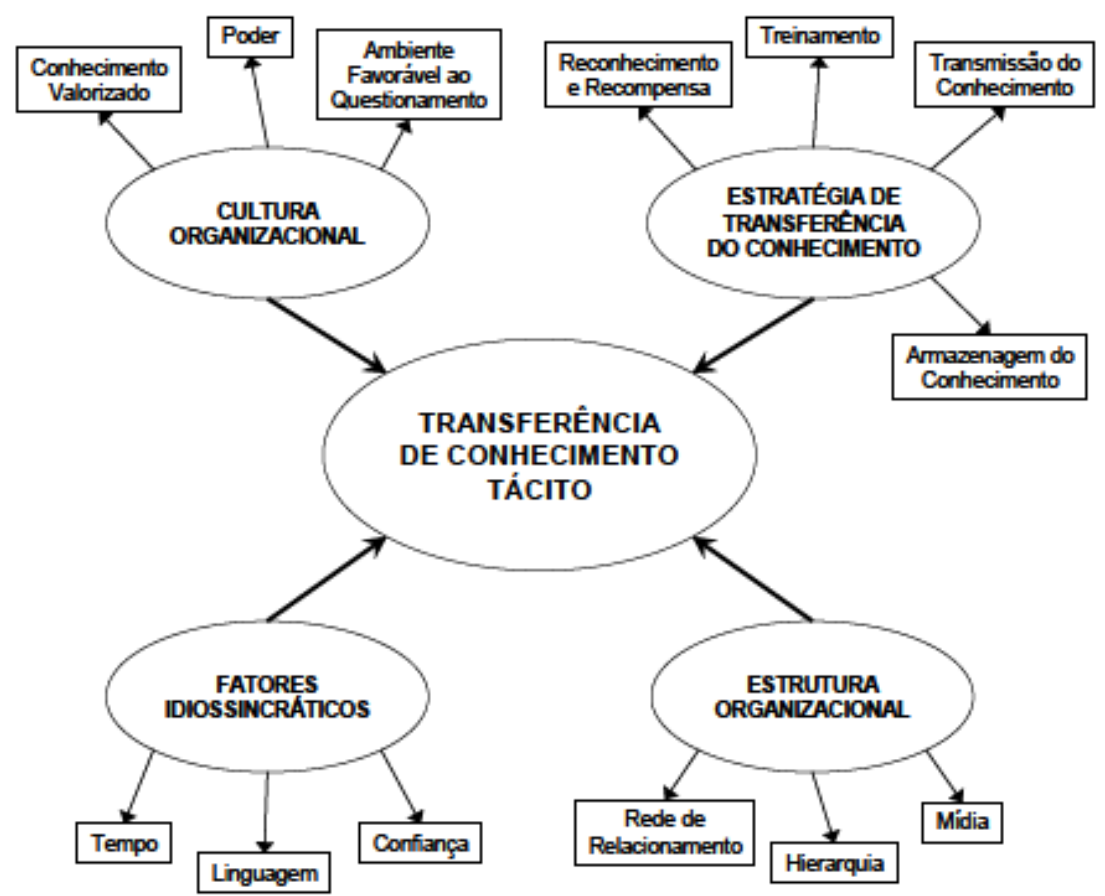

Figura 03 - Modelo heurístico de transferência de conhecimento tácito (Fonte: Lemos, 2008)

A cultura organizacional, segundo o modelo elaborado por Lemos (2008), vem como um dos indicadores para a transferência de conhecimento tácito. Lin e Lee (2006), consideram a cultura organizacional importante para a promoção do compartilhamento do conhecimento e para ocorrer de forma eficiente, se faz necessária a criação de um clima organizacional favorável, com suporte 
dos gestores no desenvolvimento de estímulos e motivação para sugestão e aplicação de novas ideias, uma comunicação transparente, bem como evidenciar a relevância da construção de confiança, segurança e recompensa no compartilhamento do conhecimento.

Lemos (2008), em seu modelo (Figura 03), aponta como alicerce para a transferência de conhecimento tácito - sobre o viés da cultura organizacional - o conhecimento valorizado, o poder e o ambiente favorável ao questionamento. O poder, segundo Davenport e Prusak (2003), pode ser utilizado como condição de poder em uma organização, isto é, o indivíduo que possui conhecimento diferenciado dos demais na organização, usufrui de grande apreço entre os demais colaboradores. Os autores ainda abordam que alguns indivíduos entendem que é vantagem o não compartilhamento de seu conhecimento, ficando assim, somente para si. Essa forma errônea de pensar, levantada por Davenport e Prusak (2003), vem de embate a Glaser (1998), que afirma que o conhecimento só possui valor se for acessado e utilizado.

Outro viés, pautado por Lemos (2008) com relação à cultura organizacional, refere-se ao ambiente favorável ao questionamento, em que se faz necessária a interação entre indivíduos e, para isso, é preciso de um ambiente favorável, seguro para expressar e conhecer opiniões e ideias distintas, não comprometendo, assim, a disseminação de conhecimento tácito em uma empresa.

$\mathrm{O}$ indicador referente à estratégia de transferência de conhecimento, segundo o modelo desenvolvido por Lemos (2008), se ramifica em quatro formas: reconhecimento e recompensa, treinamento, transmissão do conhecimento e armazenagem do conhecimento.

O reconhecimento e recompensa agem como incentivos para o compartilhamento do conhecimento. Davenport e Prusak (2003) afirmam que para constituir uma cultura robusta de compartilhamento do conhecimento, se faz necessário o uso de gratificações monetárias interessantes, aumentos de salário, promoções, entre outras formas de moeda valorosa. Joia (2006) e Lemos e Joia (2012) contribuem para isso, afirmando que se torna relevante desenvolver sistemas de avaliação de desempenho que avaliem o compartilhamento do conhecimento.

Para Marras (2001, p. 145), “treinamento é um processo de assimilação cultural a curto prazo, que objetiva repassar ou reciclar conhecimento, habilidades ou atitudes relacionadas diretamente à execução de tarefas ou à sua otimização no trabalho". Refere-se, portanto, à uma atividade estratégica que pode ser realizada de várias formas, em que a capacidade da empresa em priorizar a disseminação do conhecimento tácito faz a diferença no desenvolvimento do indivíduo e seus conhecimentos.

Com relação à transmissão do conhecimento, Hansen, Nohria e Tierny (1999), afirmam que este pode ser disseminado, com foco nas pessoas ou no reuso de conhecimento já codificado, isto é, já disseminado e compartilhado. Com o enfoque nas pessoas, a disseminação do conhecimento está na comunicação, no diálogo. Segundo Nonaka e Takeuchi (1997) e Joia (2007), é preciso que haja 
interação entre individuos, para que se possa ter contato pessoal entre eles e com isso, o conhecimento compartilhado. Já com o enfoque no reuso do conhecimento, os autores consideram que o conhecimento já está explicitado e armazenado em algum suporte de dados, para que possa ser acessado e utilizado pelos colaboradores da empresa. Indicadores pautados na estrutura organizacional, segundo Lemos, dividem-se em três vieses: rede de relacionamento, hierarquia e mídia.

Rede de relacionamento, para Lemos e Joia (2012), refere-se à forma de comunicação dentro da organização, considerada como tarefa da rede de relacionamentos da empresa, na busca de possibilidades de averiguar se as pessoas possuem os conhecimentos necessários.

A hierarquia vem de encontro com a acessibilidade dos indivíduos na organização em vivem, sendo fácil, independente do cargo ou setor em que exercem suas práticas (LEMOS; JOIA, 2012).

O fator idiossincrático refere-se a vieses relacionados à peculiaridade, ao pessoal, em que somente a própria pessoa entende, está intrinsecamente no indivíduo. Nesses fatores, encontra-se segundo Lemos (2008), o tempo, a comunicação (linguagem) e a confiança.

No mundo contemporâneo, onde a tecnologia age como facilitadora na disseminação dos dados e das informações, onde o mercado se torna cada vez mais complexo e crítico, a disponibilidade de tempo se faz escassa no mundo dos negócios. É imprescindível, então, fazer o melhor uso possível do tempo e não desperdiçá-lo. Segundo Davenport e Prusak (2003), o tempo hoje se torna um recurso escasso e não deve ser desperdiçado, a não ser em prol de um retorno interessante e que compense a empresa. O compartilhamento de conhecimento solicita tempo, pois exige interação por meio do diálogo, das experiências, reflexões. Disterer (2003) corrobora, afirmando que o compartilhamento, a disseminação do conhecimento não deve ser visto pela empresa como uma atividade extra, pois requer tempo para sua realização e reflexão sobre o conhecimento adquirido.

Segundo Tassigny et al (2012), a comunicação organizacional é um processo crucial à interação da empresa, tanto no ambiente externo, quanto interno, para o aprimoramento de seus procedimentos, para a sobrevivência mercadológica da empresa, pois permite melhor fluxo de informação. Para o bom andamento de uma organização, se faz necessária uma linguagem clara, uma comunicação aberta, pois segundo Szulanski (1996) a transferência do conhecimento tácito se faz pela linguagem, não podendo assim haver falhas de comunicação entre os indivíduos envolvidos.

Como o conhecimento tácito é inerente ao indivíduo e de difícil verbalização, se faz necessária uma relação de confiança entre os indivíduos, para que o compartilhamento seja realizado da melhor forma possível. Davenport e Prusak (2003) corroboram, afirmando que quanto 
mais confiança existir entre as partes envolvidas, menos risco e incerteza na transferência do conhecimento tácito. Por isso, se faz relevante a verificação das relações de confiança nas empresas, pois se torna essencial para a transferência de conhecimento tácito.

\section{Gestão do Conhecimento nas Pequenas e Médias Empresas - PMEs}

Segundo o IBPT - Instituto Brasileiro de Planejamento Tributário (2012) o Brasil possui atualmente 12.904.523 (Doze Milhões, Novecentos e Quatro Mil, Quinhentos e Vinte e Três) empreendimentos, incluindo seus estabelecimentos matriz e filiais. Destes, 11.663.454 são de empresas e empreendimentos privados (90\%), 1.144.081 de entidades privadas sem fins lucrativos (9\%), e 96.988 de entidades públicas governamentais (1\%). Desse total, $98 \%$ são micro e pequenas empresas (MPEs), sendo os pequenos negócios (formais e informais) responsáveis por mais de dois terços das ocupações do setor privado. Essas empresas se diferem de acordo com o número de colaboradores e seu faturamento bruto anual, conforme se pode observar no Quadro 1, abaixo:

\begin{tabular}{|l|l|c|c|}
\hline \multicolumn{1}{|c|}{ PORTE } & \multicolumn{1}{|c|}{ SETOR } & EMPREGADOS* & FATURAMENTO BRUTO ANUAL** \\
\hline \multirow{2}{*}{ Microempresa } & Comércio e serviço & Até 09 & \multirow{2}{*}{ Até R\$ 244.000,00 } \\
\cline { 2 - 3 } $\begin{array}{l}\text { Pequena } \\
\text { Empresa }\end{array}$ & Indústria e Construção & Até 19 & \multirow{2}{*}{ Entre R\$ 244.000,00 e R\$ 1.200.000,00 } \\
\cline { 2 - 3 } & Comércio e Serviço & De 10 a 49 & \\
\cline { 2 - 3 }
\end{tabular}

Quadro 1 - Classificação das MPEs segundo o número de empregados e faturamento Fonte: Sebrae, 2008.

De 2002 a 2010, a taxa de desemprego no Brasil caiu sistematicamente de 10,5\% para 5,3\%, grande parte devido às PMEs (DELOITTE, 2011). 80\% do total de vagas abertas em 2011, por exemplo, vieram das PMEs (PORTAL BRASIL, 2011). Estas PMEs certamente souberam aproveitar o novo ambiente de negócios brasileiro, mais propício ao desenvolvimento do país, mas como tal, cercado de oportunidades e, também, de ameaças.

Mesmo com limitados recursos, de toda ordem, estas PMEs souberam, principalmente, garantir a rentabilidade de seus negócios, adaptar a sua estrutura operacional e orgânica, desenvolver produtos e serviços de valor percebível, suportar financeiramente suas operações e projetos, adotar sistemas integrados e estratégicos de gestão, atrair, investir e reter talentos, gerir o conhecimento, promover a inovação e, ainda, alcançar custos e preços competitivos, fortalecendo a suas posições de mercado. Enfim, asseguraram a sua sobrevivência e o seu crescimento (NORTH, DA SILVA NETO, DÁVILA CALLE, 2013).

No que se refere à gestão do conhecimento, estas PMEs criaram condições para o compartilhamento do conhecimento, não só daquele acumulado e disseminado ao longo da sua existência organizacional, como também, e principalmente, daquele ainda implícito (tácito), de 
posse individual de seus integrantes, não explicitado, não compartilhado espontânea e horizontalmente com toda a equipe (NORTH, DA SILVA NETO, DÁVILA CALLE, 2013).

Navegar com habilidade e eficiência em mares revoltos, fugindo da deriva e aproveitando os bons ventos para imprimir velocidade, é tarefa difícil, que exige planejamento, capacitação e constante aprimoramento. Esse tem sido o desafio enfrentado pelos comandantes das pequenas e médias empresas brasileiras nos turbulentos oceanos de um mercado em intensa competição. (DELOITTE, 2008).

Enfim, estas empresas precisam manter e aproveitar seus talentos humanos para crescer, desenvolver suas competências, buscar sustentabilidade e rentabilidade, mediante as ações estratégicas de transferência do conhecimento, com uma cultura e estrutura organizacional adequada, para trabalhar com os fatores idiossincráticos (tempo, linguagem e confiança) com o propósito de máximo aproveitamento do potencial de sua equipe, o seu capital intelectual.

O Brasil, já livre das mazelas do subdesenvolvimento mais explícito, está, ainda, infelizmente, longe da modernidade. Temos, hoje, problemas muito melhores do que os do passado. A produtividade brasileira, por exemplo, é o grande desafio, o grande calcanhar de aquiles. Através do conhecimento organizacional, atualmente, o principal fator de produção, de agregação de valor, de produtividade e de crescimento das empresas [REVISTA EMPREENDEDOR, 2013], será possível a construção de um Brasil mais competitivo.

\section{Procedimentos Metodológicos}

Trata-se de uma pesquisa qualitativa, de caráter exploratório e descritivo, classificada também como de campo e bibliográfica.

Conforme Honorato (2004, p. 97), a pesquisa qualitativa "proporciona melhor visão e compreensão do contexto do problema. [...] e caracteriza-se pela análise psicológica dos fenômenos de consumo, pela explicação das razões pelas quais se age de determinado modo e pela impossibilidade de quantificação."

Taylor e Bogdan (1997) afirmam que

Pesquisadores qualitativos estão preocupados com os significados que as pessoas atribuem às coisas nas suas vidas. O objetivo da pesquisa qualitativa é certificar-se de que a teoria se ajusta aos dados e não vice-versa. Na metodologia qualitativa, os pesquisadores examinam as definições e as pessoas holisticamente; pessoas, configurações ou grupos não são reduzidos a variáveis, mas são vistas como um todo.

Compreende a pesquisa como de caráter exploratório, conforme Severino (2007, p. 123), aquela que "busca apenas levantar informações sobre um determinando objeto, delimitando assim um campo de trabalho mapeando as condições de manifestações desse objeto.”

Classificada também como descritiva, por descobrir de forma aprofundada e com mais precisão, o modo com que o fenômeno acontece na organização, procurando explicá-lo e descrevê- 
lo. Para Gil (2002, p. 44) este tipo de pesquisa "têm como objetivo primordial a descrição das características de determinada população ou fenômeno ou o estabelecimento de relação entre variáveis." Considera-se então um estudo descritivo, pois busca identificar, descrever e analisar as principais indicações teóricas acerca da influência do compartilhamento do conhecimento no desenvolvimento das competências das organizações.

A pesquisa de campo, segundo Lakatos e Marconi (2009, p. 83), refere-se a uma pesquisa que possui como "objetivo o de conseguir informações e/ou conhecimento acerca de um problema para o qual se procura uma resposta, ou de uma hipótese que se queira comprovar, ou, ainda descobrir novos fenômenos ou as relações entre elas."

O presente estudo também pode ser classificado como uma pesquisa bibliográfica, pois para uma melhor compreensão em relação à pesquisa proposta, se fez necessário utilizar a pesquisa bibliográfica, a qual consiste na fundamentação teórica da literatura e revisão bibliográfica.

É considerado um estudo de campo, por realizar sua investigação em nove organizações, compostas por pequenas e médias empresas industriais de Jaraguá do Sul, no estado de Santa Catarina/Brasil, sendo os sujeitos da pesquisa os proprietários das empresas. O número de participantes foram 12 colaboradores, caracterizando-se a aplicação da pesquisa à população da organização em estudo. Para Roesch (1999, p. 138) "população é um grupo de pessoas ou empresas que interessa entrevistar para o propósito específico de um estudo.”

Segundo Lakatos e Marconi (2009, p. 165), a coleta de dados é a "etapa da pesquisa em que se inicia a aplicação dos instrumentos elaborados e das técnicas selecionadas, a fím de se efetuar a coleta dos dados previstos." Para essa pesquisa utilizou-se uma coleta de dados proveniente de pesquisa bibliográfica, entrevista semiestruturada e observação.

Com relação à entrevista semiestruturada como instrumento para a coleta dos dados, Gil (2008, p. 111) pondera que "a entrevista é seguramente a mais flexível de todas as técnicas de coleta de dados de que dispõem as ciências sociais.” Já Triviños (2007, p. 146), refere-se:

àquela que parte de certos questionamentos básicos, apoiados em teorias e hipóteses, que interessam à pesquisa, e que, em seguida, oferecem amplo campo de interrogativas, fruto de novas hipóteses que vão surgindo à medida que se recebem as respostas do informante. Desta maneira, o informante, seguindo espontaneamente a linha de seu pensamento e de suas experiências, dentro do foco principal colocado pelo investigador, começa a participar na elaboração do conteúdo da pesquisa.

Lapolli (2010) pondera que nesse tipo de coleta de dados não precisa estabelecer uma ordem rigorosa dos questionamentos, pois novas questões podem ser levantadas no decorrer das entrevistas, permitindo assim, mais informações, que no decorrer das entrevistas se fazem necessárias para a pesquisa, a boa condução e o aprofundamento da investigação. É importante salientar que as entrevistas, foram realizadas de forma individual e reservada, a fim de permitir confidencialidade e liberdade de arguição. 
O objetivo deste artigo é caracterizar e analisar algumas formas de interação social utilizadas em pequenas e médias empresas que, através de estímulos, motivação e incentivos, potencializam o compartilhamento e a reutilização de conhecimentos tácitos, fazendo a maioria dos funcionários se sentirem pertencentes e úteis à empresa. Foram, assim, elaboradas perguntas compostas por questões abertas com os proprietários de pequenas e médias empresas industriais de Jaraguá do Sul, fundamentadas em autores que abordam os temas de compartilhamento e reutilização do conhecimento. Os conteúdos das gravações das entrevistas, com tempo médio de 37 minutos, cada uma delas, foram, após, transcritas, lidas e analisadas.

A pesquisa de campo, baseada no método de pesquisa em profundidade, envolveu 09 indústrias pequenas (até 99 funcionários) e médias (até 499 funcionários) de Jaraguá do Sul/SC, dos setores metal mecânico (03), químico (03) e móveis (03), fundadas entre 1972 e 1997, com faturamentos anuais entre 8 e 170 milhões de reais.

A entrevista em profundidade tem como objetivo compreender as perspectivas dos informantes sobre suas vidas, experiências, ou situações, expressas em suas próprias palavras. Flexível, dinâmica, não diretiva, não estruturada, sem padrão fixo e semiaberta a entrevista em profundidade é apropriada quando os interesses da pesquisa são relativamente claros e bem definidos. (TAYLOR; BOGDAN, 1997).

A pesquisa de campo realizada é representativa porque o município é o $3^{\circ}$ maior polo industrial (só ficando atrás de Joinville e Blumenau) e o $5^{\circ}$ maior PIB (Produto Interno Bruto) do estado de Santa Catarina (sendo Joinville, Itajaí, Florianópolis e Blumenau, os maiores) [IBGE, 2010]. Além disso, Jaraguá do Sul é um dos poucos municípios de Santa Catarina, em que o PIB do setor secundário (indústrias de transformação) é superior aos PIBs de serviços e de agropecuária: $47 \%$ contra $40 \%$ e $13 \%$, respectivamente [IBGE, 2010].

No que tange a pequenas e médias empresas, elas representam em Jaraguá do Sul 99\% do total de empresas instaladas no município, empregam cerca de 53\% do total de pessoas ativas e participam com cerca de 13\% do PIB total (SEBRAE SC, 2013).

Os entrevistados, todos sócios-proprietários, homens, entre 35 e 72 anos de idade, oito da primeira geração e um da segunda geração, têm formação escolar bem diversificada: três com cursos de pós-graduação, cinco com ensino médio e um sem escolaridade formal alguma.

Para tal, desenvolveram-se as seguintes perguntas de pesquisa como norteadoras para o estudo proposto:

- Como se dá a captação, o compartilhamento, a implantação e a reutilização dos conhecimentos relativos ao seu core business?

- Qual a sua percepção quanto à existência - ou não - de conhecimentos tácitos em sua empresa? 
- Quais os seus instrumentos, meios e formas de compartilhamento e reutilização de conhecimentos tácitos, de forma a evitar perdê-los ?

Posteriormente, realizou-se o processo de análise e interpretação dos dados coletados que, segundo Triviños (2008), apoia-se nos resultados alcançados no estudo, na fundamentação teórica e na experiência pessoal dos investigadores. Como estratégia de interpretação, foi utilizada análise de conteúdo.

\section{Análise e Interpretação dos Dados}

Os Quadros 1, 2 e 3 referem-se à análise de conteúdo coletados a partir das entrevistas relacionadas.

Quadro 1 - Análise de conteúdo do questionamento 1: Onde a sua empresa busca conhecimento e como é feita a captação para o seu core business?

\begin{tabular}{|c|c|}
\hline $\begin{array}{l}\text { ATORES DA } \\
\text { PESQUISA }\end{array}$ & \\
\hline A1 & $\begin{array}{l}\text { [...] Mas, a grande captação de conhecimento se dá nas feiras, levando o máximo possível do } \\
\text { nosso pessoal e sempre após feiras, cursos e palestras, peço ao pessoal que teve a chance de } \\
\text { ir, para fazer uma espécie de resumo e compartilhar com pessoas dos setores e os } \\
\text { encarregados. A gente tem que trocar com outros estas ideias que eles aprenderam. [...] } \\
\text { entrego e digo para eles ficarem uns dois dias para uma lida e, se tiver alguma ideia, trazer } \\
\text { para a gente. E, além disso, gosto de fazer uma reunião específica sobre aquele evento que as } \\
\text { pessoas participaram (palestras, curso, feira). } \\
\text { Usamos, também, catálogos e folders [...] }\end{array}$ \\
\hline A2 & $\begin{array}{l}\text { [...]buscamos principalmente em cursos e palestras, em São Paulo e Porto Alegre [...] como } \\
\text { somos associados de uma entidade, ABTB - Associação Brasileira de Tecnologia da } \\
\text { Borracha, também participamos de feiras. O que mais buscamos de conhecimento teórico, } \\
\text { contudo, são em boletins, palestras e cursos promovidos pela ABTB. [...] É uma área que } \\
\text { exige de nós muita dedicação ao desenvolvimento, sem ter apoio externo. [...] } \\
\text { A busca do conhecimento começou comigo. Participei de muitos cursos e trabalhei muito. } \\
\text { Depois com este conhecimento teórico [...] unimos o que eu tinha de conhecimento teórico na } \\
\text { formulação e passei isto a ele para transformar, na prática, em composto de borracha, que é } \\
\text { uma mistura. [...] com essa junção, minha na parte de desenvolvimento do produto na área } \\
\text { mais técnica, mais química, e com a parte mais prática dele, nós conseguimos criar a } \\
\text { empresa, alavancar e ir adiante. [...] }\end{array}$ \\
\hline A3 & $\begin{array}{l}{[\ldots] \text { Vamos, é claro, a muitas feiras internacionais, visitamos outras empresas, dependendo da }} \\
\text { situação, até compramos projetos, são poucos, a grande maioria dos projetos é desenvolvida } \\
\text { em casa. Nós temos hoje uma área de P\&D, que vai, inclusive ter um CNPJ separado para } \\
\text { desenvolver produtos para nós e para terceiros. [...] }\end{array}$ \\
\hline A4 & $\begin{array}{l}\text { A gente está sempre atento ao mercado. Participo de feiras, mais internacionais, lá que a } \\
\text { gente busca as tendências, principalmente de revestimentos. [...] Há, também, o feeling de } \\
\text { captar as coisas do mercado, visitando clientes, fotos de clientes, vendo ideias deles. É desta } \\
\text { maneira que a gente vai fazendo. E, claro, também com designers que a gente sempre teve na } \\
\text { empresa, desde o início. E eles acabam trazendo as ideias e a gente modificando alguma } \\
\text { coisa e tal, trazendo para a realidade de mercado. [...] Fora os designers, não usamos } \\
\text { consultores. } \\
\text { Nas feiras internacionais, nós vemos produtos de fabricantes de estofados a nível mundial, } \\
\text { vendo o que estão fazendo, lançando e sentindo tendências. A Itália, no ramo de móveis, é a } \\
\text { que lança tendências. [...] }\end{array}$ \\
\hline A5 & $\begin{array}{l}\text { Visitando diversas feiras e, também, a Weg, onde trabalhei } 21 \text { anos, meu único emprego, [...] } \\
\text { Comecei na área de montagem, fui para a área de laboratórios, depois manutenção, onde } \\
\text { passei por todos os setores da indústria e se conhece tudo, desde a sala do presidente ao } \\
\text { produto acabado, onde aprendi muito. [...] } \\
\text { E, constantemente, em visitas a Hannover, vendo os produtos e tecnologias novas, pegando }\end{array}$ \\
\hline
\end{tabular}




\begin{tabular}{|c|c|}
\hline & $\begin{array}{l}\text { catálogos [...] A gente vê isso em feiras e fornecedores oferecendo estas tecnologias. } \\
\text { [...] Tivemos uma experiência de busca de tecnologia na Universidade Federal de Santa } \\
\text { Catarina. Levamos um produto lá, mas não se chegou aonde queríamos. [...] É o nosso } \\
\text { gerente industrial e futuro diretor. Ele ajuda a desenvolver, visita clientes, ajuda a área de } \\
\text { projetos e faz um acompanhamento geral na produção, ajuda a elaborar propostas de grande } \\
\text { porte [...]. }\end{array}$ \\
\hline A6 & $\begin{array}{l}\text { Buscamos o conhecimento em feiras e aquisição de produtos de outros países, reunião de } \\
\text { conhecimentos com os designers e na área interna de desenvolvimento de produtos. } \\
\text { Quanto ao processo (conhecimento), isto já vem de longos anos e a sequência, o fio da } \\
\text { meada, é sempre o mesmo. }\end{array}$ \\
\hline A7 & 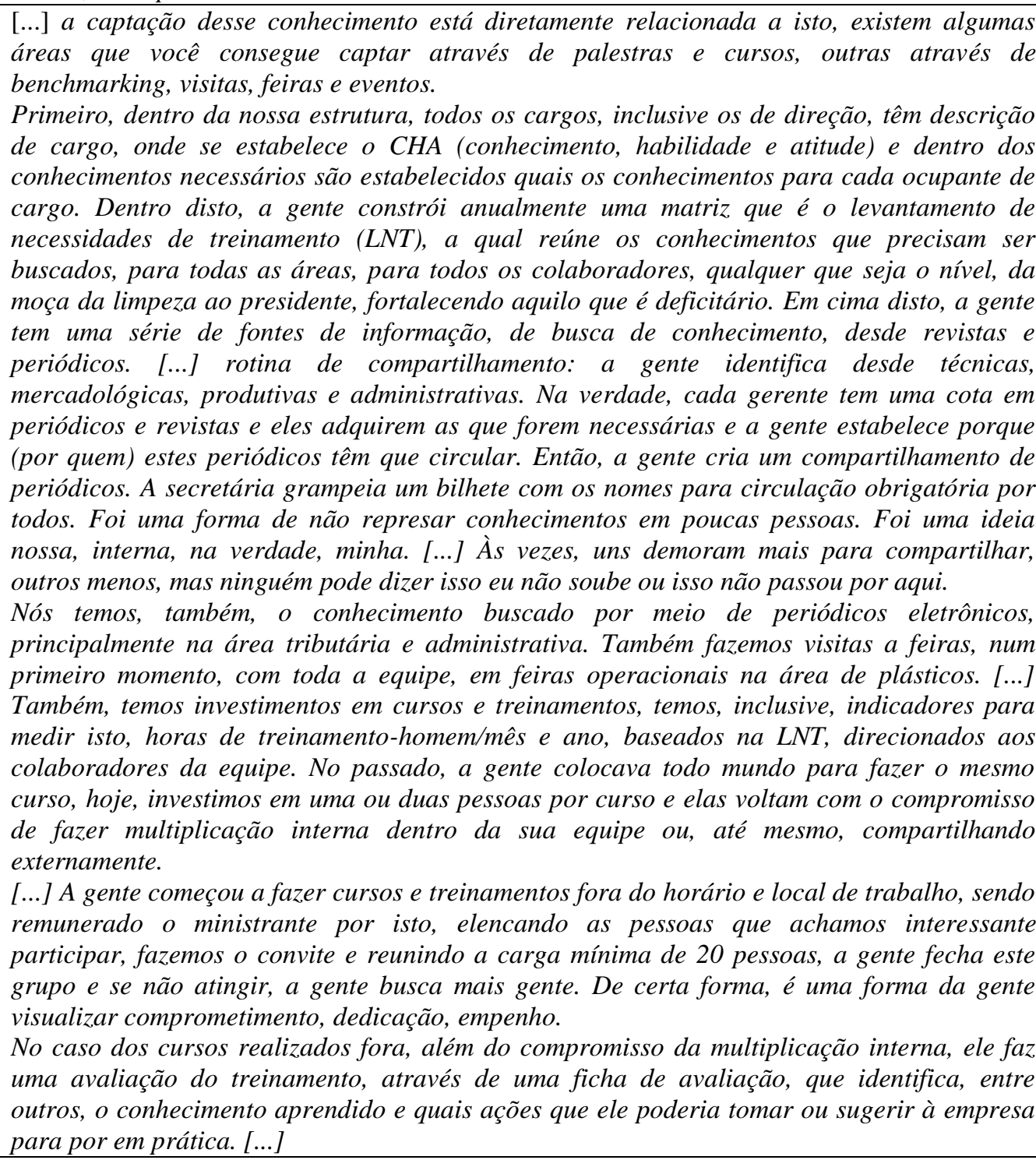 \\
\hline A8 & $\begin{array}{l}\text { Hoje, as nossas referências seriam as feiras internacionais. Nós participamos dos maiores } \\
\text { eventos a nível mundo, por exemplo, a de Milão. [...] Hoje temos um escritório (de design) em } \\
\text { Porto Alegre, que trabalha em parceria, mas não temos uma dependência 100\% deste } \\
\text { escritório. Nós fizemos uma estratégia de combinar os dois fatores, o interno e o externo. Nós } \\
\text { temos vários produtos que são criados por nossa equipe interna, baseada no banco de } \\
\text { informações que formamos e também produtos criados por este escritório. [...] } \\
\text { Vamos formando um banco de dados, que é compartilhado com este escritório, também, para } \\
\text { ver se a gente fala a mesma linguagem. Quando vem para dentro da fábrica, é feita uma } \\
\text { reunião, uma dinâmica de grupo e a gente faz um panorama geral do que se viu em } \\
\text { tendências. Partindo daí, se cria uma proposta de criaçôes. Às vezes, esta proposta nem vem } \\
\text { de dentro da empresa, vem de clientes que são ícones na parte do segmento em inovação, que } \\
\text { viajam muito para lá, que trabalham com produtos importados e eles próprios já começam a } \\
\text { finalizar. [...] se eu quiser alterar qualquer coisa em um produto, esquece. Eu vou ter que } \\
\text { fazer uma solicitação, via ficha de alteração, para o comitê de engenharia dar o OK ou não e } \\
\text { fazer uma triagem. Muitas vezes o meu próprio voto é um voto vencido e me dou por } \\
\text { tranquilo, sem problema algum. [...] }\end{array}$ \\
\hline
\end{tabular}


Nós participamos de quase todas as feiras. E nestas feiras, a gente busca a tecnologia para fazer aqui. [...] Então, eu faço uma pesquisa, que é feita aqui comigo mesmo, onde num laboratório aqui, se faz o teste com os produtos, com formigas e insetos em geral e depois a gente lança no mercado. Temos laboratórios em São Paulo, como o IPT e o Bioagro, que fazem as análises: matou 100\%, matou 80\%; e aí, a gente lança no mercado. [...]

Quadro 2 - Análise de conteúdo do questionamento 2: Como é feito o compartilhamento, implantação ou reutilização do conhecimento para o core business da sua empresa?

\begin{tabular}{|c|c|}
\hline $\begin{array}{c}\text { ATORES DA } \\
\text { PESQUISA } \\
\end{array}$ & \\
\hline A1 & $\begin{array}{l}\text { Nós temos métodos e processos. [...] Para cada processo de trabalho, existe uma folha } \\
\text { dizendo para aquela pessoa que está ali trabalhando como ela tem que trabalhar. [...] } \\
\text { Logicamente, que tem que ter um ensinamento pelo encarregado ou por pessoas mais antigas } \\
\text { na empresa. E a todo funcionário que entra na empresa, nós damos um treinamento de quase } \\
\text { O1 dia, numa miniescolinha aqui na empresa, sobre direitos e obrigaçoses, normas, } \\
\text { procedimentos e apresentamos todos os setores da empresa e, aí, a gente dá as normas de } \\
\text { procedimento de trabalho para cada um. } \\
\text { Quando a gente vê que há abertura para a implantação de um novo produto, uma nova } \\
\text { máquina, eu procuro mandar a pessoa especializada daqui e que vai poder usar no futuro, se } \\
\text { a gente comprar este conhecimento ou esta máquina, para esta empresa, seminário ou feira, } \\
\text { indo um, dois ou três engenheiros do departamento de engenharia, junto com os } \\
\text { encarregados e as pessoas chaves no setor. [...]. Faço questão que uma pessoa ou duas, } \\
\text { encarregados ou líderes, que possam usar aquele conhecimento ou máquina, ou um } \\
\text { engenheiro, se é algo totalmente novo, ou, às vezes, até eu, para conhecer e dizer, sim, dá } \\
\text { para implantar, não dá para implantar. Aí, sim, se aprovado, eu jogo um setor todo, para } \\
\text { todos saberem o que está acontecendo. Eu gosto de envolver todo o pessoal, também quando } \\
\text { há uma mudança de processo, de norma ou produto, fazendo reuniões lá dentro, no chão de } \\
\text { fábrica. [...] }\end{array}$ \\
\hline A2 & $\begin{array}{l}\text { Fazemos reuniões, trocas de ideias, mas aquilo que se busca lá fora, hoje, mais pelo meu } \\
\text { filho, de cursos e palestras, tem que decidir se é aplicável ou não para nós e se sim, transfere- } \\
\text { se o conhecimento para a área industrial, para ensaios, principalmente de produtos. [...] } \\
\text { Estando comprovado que este resultado está bom, se faz a transferência aos operadores, para } \\
\text { que eles tenham em mãos o procedimento para fazer o tal composto. [...] }\end{array}$ \\
\hline $\mathbf{A 3}$ & $\begin{array}{l}\text { Hoje, todo conhecimento entra pelo } P \& D \text {, que tem todo um procedimento para arquivar } \\
\text { todos estes projetos, para desenvolver protótipos, numa minifábrica, e fazer testes de campo. } \\
\text { O produto aprovado, ele passa a integrar a produção. Como são três fábricas, com produtos } \\
\text { diferenciados, este conhecimento é compartilhado com as engenharias das fábricas, que } \\
\text { consolidam estes projetos e põem em linha de produção. [...] }\end{array}$ \\
\hline A4 & $\begin{array}{l}\text { [...] Até no ano passado, tínhamos um designer interno. Inclusive este designer interno } \\
\text { compartilhava com o que trazíamos lá de fora e dentro disto aí, ele captava as ideias e fazia } \\
\text { algo baseado no modelo trazido. Às vezes saia algo completamente diferente. A gente não } \\
\text { copia, a gente cria, é a ideia. A gente faz diferente, vendo o que o mercado brasileiro vai } \\
\text { aderir. } \\
\text { [...] Como a gente tem uma feira por ano, que é em fevereiro e, depois, a feira da Itália, de } \\
\text { Milão, em abril, normalmente alguém vai nesta feira, daí traz estes conhecimentos, das } \\
\text { pesquisas que a gente faz lá e daí a gente já começa a trabalhar em cima da próxima coleção, } \\
\text { que é em fevereiro. [...] A gente faz um briefing do negócio, dá ideias para o designer e a } \\
\text { equipe interna começa a trabalhar em cima [...] }\end{array}$ \\
\hline A5 & $\begin{array}{l}\text { Fazemos reuniões a cada quinze dias, diretorias, gerências e chefias e os desafios que vão } \\
\text { aparecendo no dia-a-dia fazemos experimentos internamente, testando e aí chamamos o } \\
\text { cliente: é isto o que você quer? Pode fabricar? Está de acordo? Assina. Nas feiras, vão o } \\
\text { Júnior e toda a equipe de projetos e veem o que tem de novo em tecnologia e trazem para nós. } \\
\text { Eles se separam, de dois em dois, e vão visitar diferentes clientes. Todos trazem catálogos, } \\
\text { senta e mostra. [...] Voltando das feiras, o que é interessante? [...] }\end{array}$ \\
\hline A6 & $\begin{array}{l}\text { Faz-se reuniões a partir de folders, se dá uma analisada o que pode ter por trás daquilo, } \\
\text { porque uma fotografia só mostra a parte externa e daí se junta conhecimentos e experiências. } \\
\text { A partir dali vai-se colocando no papel até sair o produto. } \\
\text { Sempre junto com toda a área de desenvolvimento. Tudo é conversado, debatido o que foi } \\
\text { visto, o que se achou, onde a gente está na frente. Às vezes, a gente vai a uma feira e não há } \\
\text { nada de mais interessante do que já temos. Aquele produto, aquele sistema, o nosso está mais } \\
\text { avançado, tem melhor qualidade. Isto acontece muitas vezes. } \\
\text { Normalmente, a área de vendas solicita um breefing do produto e deste a gente vai adaptando }\end{array}$ \\
\hline
\end{tabular}




\begin{tabular}{|c|c|}
\hline & o conhecimento que a gente tem, vai botando no papel e depois desenvolve tudo [...] \\
\hline A7 & $\begin{array}{l}\text { Esta é uma preocupação bastante grande não só na questão de como gerar um novo negócio, } \\
\text { porque a partir do momento que uma ideia vira um novo negócio, ela tem um trâmite interno } \\
\text { de desenvolvimento, a gente faz a gestão de projeto e dentro disso a gente tem um grupo } \\
\text { interno para inovação e desenvolvimento, seja para novos produtos e novos processos. Esses } \\
\text { grupos se reúnem quinzenalmente. Assim, quando surge uma ideia, ela vira um projeto novo, } \\
\text { que é documentado, registrado e o risco de se perder e muito pequeno, por causa do registro } \\
e \text { documentação interna. E existem ideias que não viram projetos. Viram gaveta e } \\
\text { esquecimento. Entâo, essa é uma grande dificuldade. [...] }\end{array}$ \\
\hline A8 & $\begin{array}{l}\text { Nós temos um comitê que tem a competência principal da empresa. [...] Tudo é documentado } \\
\text { em processo que é onde se vai oficializar o conhecimento da empresa. [...] faz-se uma análise } \\
\text { crítica de todos os aspectos dele: a costura, o acabamento, o conforto, a dimensão, a } \\
\text { ergonomia. [...] O segredo do sucesso é fugir da tal comoditizaçâa, porque em commodities o } \\
\text { que define é o preço e quem tem uma empresa } 100 \% \text { regularizada nunca é competitiva. Ou } \\
\text { seja, tem-se, sempre, que buscar liderar pela inovação. [...] }\end{array}$ \\
\hline A9 & $\begin{array}{l}\text { Existe o nosso departamento de registro, onde temos armazenada a formulação, que é sigilo. } \\
\text { Duas a três pessoas, no máximo, que estão a par do produto. A gente passa para os } \\
\text { formuladores, lá dentro, somente como tem que ser feito. [...] }\end{array}$ \\
\hline
\end{tabular}

Quadro 3 - Análise de conteúdo do questionamento 3: Há (muitos) conhecimentos tácitos em sua empresa? E o que é feito para explicitá-los?

\begin{tabular}{|c|c|}
\hline $\begin{array}{c}\text { ATORES DA } \\
\text { PESQUISA }\end{array}$ & \\
\hline A1 & $\begin{array}{l}\text { Temos sim, conhecimentos tácitos na empresa, [...] estamos mudando muito do conhecimento } \\
\text { tácito para o papel, mas nem tudo a gente consegue passar para o papel, porque tem aquele } \\
\text { tipo de conhecimento que é um sexto sentido, que ele acha que é assim e ele vão pelo intuito } \\
\text { dele. [...] procura colocar todo o conhecimento no papel, até para aquela situação em que o } \\
\text { cara saiu e o novo vai entrar, ele já sabe como vai funcionar só lendo o documento que está } \\
\text { na bancada dele. [...] Existem muitos funcionários que acham eles não devem passar este } \\
\text { conhecimento, senão perde o cargo, a função ou são demitidos, mas a gente procura mostra } \\
\text { para eles que não é bem isso. O que se quer é documentar para que seja uma norma, uma } \\
\text { coisa mais organizada, mais funcional. [...] }\end{array}$ \\
\hline A2 & $\begin{array}{l}\text { Tem. Lamentamos em algumas ocasiões por estas ideias, estes conhecimentos não terem } \\
\text { chegado de uma forma mais rápida até nós. Em várias oportunidades, nós já percebemos isto. } \\
\text { Eles aprendem na operação, percebem que poderia ser melhorado se fizesse de uma forma } \\
\text { diferente e eles dificilmente trazem. [...] esta sugestão e nós normalmente colocamos em } \\
\text { prática. Em muitas ocasiões, conseguimos sucesso. Então, existe, sim, este conhecimento } \\
\text { (tácito) que ele adquiriu ali, fazendo, percebendo, mas estava com ele. [...] hoje temos muitas } \\
\text { reuniões com esta finalidade, porém não com os operacionais diretamente, mas temos com o } \\
\text { pessoal da qualidade, com os líderes e o pessoal da área técnica. [...] }\end{array}$ \\
\hline A3 & $\begin{array}{l}\text { Sem dúvida alguma, percebe-se isto claramente que tem muito (conhecimento tácito). Tem } \\
\text { pessoas que não se expressam por dois motivos: por serem extremamente tímidos, têm medo } \\
\text { de se expressar. E tem aqueles que seguram a informação mesmo, por natureza, cada um com } \\
\text { seu jeito. Mas a grande maioria das informaçôes fica retida porque a pessoa não tem tido } \\
\text { oportunidade para se expressar e que têm uma atitude muito tímida. Isto aconteceu várias } \\
\text { vezes. Eu incentivo muito o pessoal a participar. A gente dá muita liberdade. Às vezes, isto só } \\
\text { vem, quando a pessoa consegue falar só comigo. Em grupo, às vezes a pessoa tem dificuldade } \\
\text { de se expressar. E, muitas vezes, a pessoa espera conversar com você pessoalmente. E eu dou } \\
\text { muita atenção para isso. Eu realmente me dedico a isto. E, quando a pessoa pede para falar } \\
\text { comigo, pessoalmente, é porque ele tem algo a me dizer. [...] dou acesso livre, todos têm meu } \\
\text { celular, meu e-mail. Liguei para ele, marcamos, conversamos e ficamos muito surpresos com } \\
\text { a informação que esta pessoa tinha e que ninguém tinha se flagrado. } \\
\text { [...] temos alguns programas internos, como o SOL (Segurança, Organização e Limpeza) e o } \\
\text { CCQ, caixinhas de sugestões (podendo se identificar ou não) que vão para um grupo, do qual } \\
\text { faço parte. E saem coisas muito interessantes. [...] }\end{array}$ \\
\hline A4 & $\begin{array}{l}\text { Aqui na nossa empresa não existe no nível operacional. [...] a gente cria aqui dentro, o resto } \\
\text { é pelos designers, que a gente tem até para ter o nome. [...] } \\
\text { A maioria das melhorias partiu de mim ou do gerente da fábrica. [...] Eu desço lá embaixo e } \\
\text { vejo que eles estão fazendo de forma errada. Eu ensino como fazer a coisa. [...] O difícil é é } \\
\text { afinar ele para ficar do jeito que tem que ser. Esse tipo de conhecimento fica mais com a } \\
\text { gente [...] }\end{array}$ \\
\hline A5 & Tem. Eu vejo em todas as empresas, não só aqui. Volta e meia, a gente faz reunião com o \\
\hline
\end{tabular}




\begin{tabular}{|c|c|}
\hline & $\begin{array}{l}\text { pessoal e eles vão passando. [...] temos uma caixa de sugestões, que ele vai depositando, mas } \\
\text { não precisa colocar o nome. [...] } \\
\text { Às vezes, também, se está consertando uma máquina, se faz de tudo e não tem jeito de } \\
\text { identificar. Aí chega um rapazinho, mas esse cabo que sai aqui do painel e vai até na bobina, } \\
\text { será que ele não está interrompido? Seis dias trabalhando em cima e os caras já enrolando o } \\
\text { estômago de tanto sofrimento e stress. Dito e feito. Num minuto se resolve. Mas este cabo } \\
\text { nunca interrompeu, mas pode ter uma primeira vez. [...] }\end{array}$ \\
\hline A6 & $\begin{array}{l}\text { Não, muito pouco. Nesta parte de lançamento de produtos, eu já era para ter me aposentado } \\
\text { dez anos atrás, mas, não, eles dizem o senhor tem que ficar aqui porque o sofá que o senhor } \\
\text { lança é o que vende. Infelizmente, até hoje, nenhum arquiteto conseguiu lançar um produto } \\
\text { que durasse tanto tempo no mercado, que tivesse tanta venda quanto os produtos que eu } \\
\text { lanço, que eu desenvolvo. } \\
\text { [...] Cheguei aqui e disse para o chefe do desenvolvimento, olha isto aqui o que sonhei esta } \\
\text { noite. [...] Daí, aprimoramos, dei prá ele e disse, não demora. Dobra mais um pouco prá cá, } \\
\text { prá lá, e faz seis anos que era o modelo campeão de vendas. } \\
\text { [...] Nós fazemos reuniões. Com os protótipos prontos, eles vão para o treinamento da } \\
\text { produção, as partes mais simples e as partes mais complexas. Aí, eles vão sugerindo os } \\
\text { acertos, dando palpites. De vez enquanto, aparece (alguma ideia). Surge esta ideia dele numa } \\
\text { determinada situação. É sempre dada oportunidade para ele sugerir, sim. } \\
\text { [...] E quem queira, pode dar sugestão. Não é aberta a garganta e enfiado lá dentro, há } \\
\text { participaçáa deles. Ele (o funcionário) póe (a ideia) para fora, quando aparece a } \\
\text { oportunidade. Nós temos o CCQ. }\end{array}$ \\
\hline A7 & 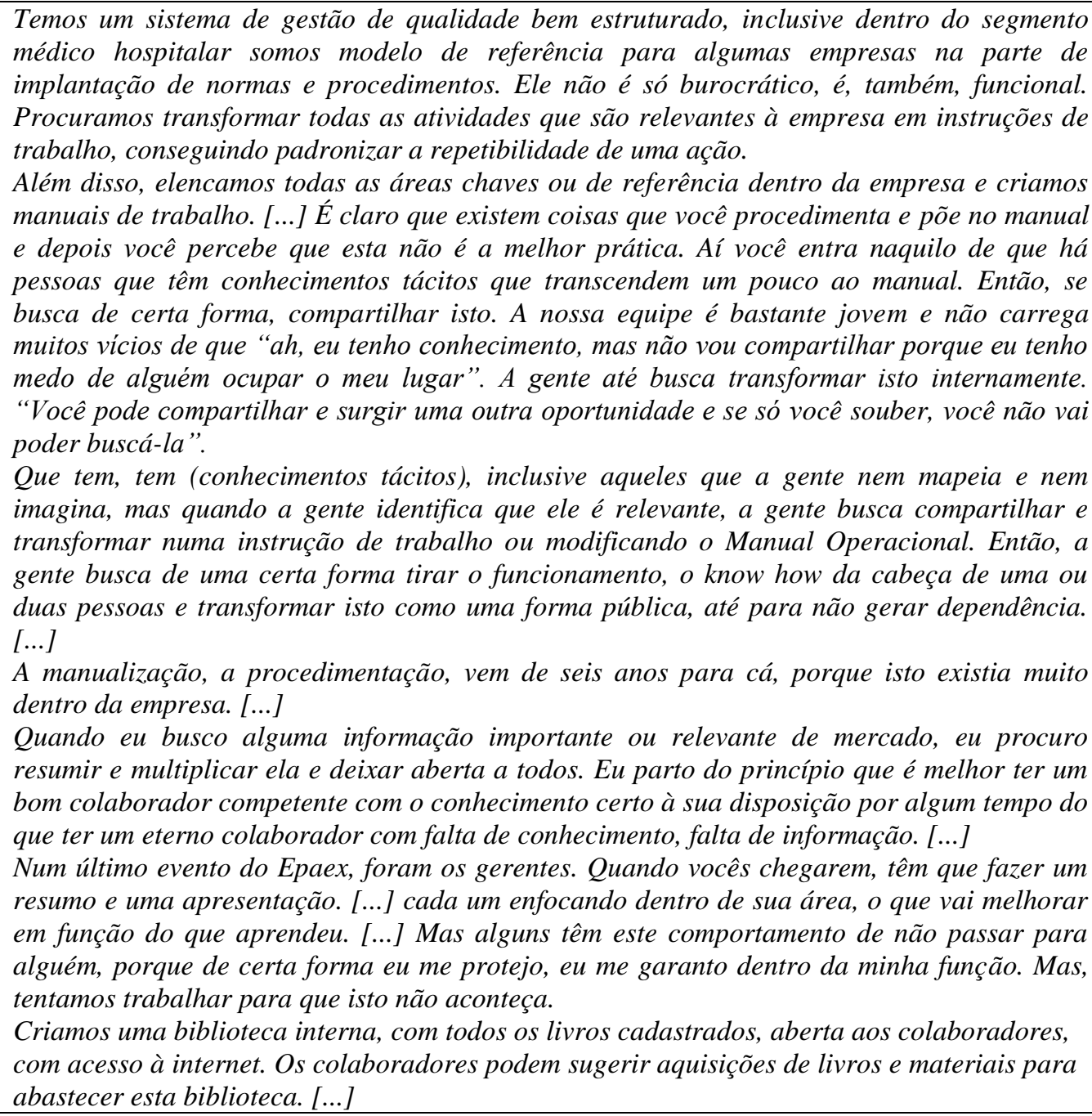 \\
\hline A8 & $\begin{array}{l}\text { Já aconteceu do conhecimento estar muito solto pela empresa. [...] Mas nos dois últimos } \\
\text { anos, passamos por um processo de normatização muito grande, normas, procedimentos. } \\
\text { Hoje, para se mover um grampo, garanto, há uma norma. } \\
\text { Hoje temos utilização de códigos de barras em todo o processo, para um total rastreamento } \\
\text { de problemas, até chegar a fornecedores. Pode-se fazer um recall em todo o lote de produtos. } \\
\text { Por sermos uma empresa pequena e darmos um grau de liberdade muito grande e eu } \\
\text { incentivo muito isto, acredito que existe (conhecimento tácito não explicitado), mas pouco. A }\end{array}$ \\
\hline
\end{tabular}


maioria das pessoas se sente muito à vontade e eu prego muito à pessoas que somos um time e o que importa é o resultado final. Em cima desta abordagem e, conhecendo as lideranças que temos dentro da empresa, eu vejo que há pouco (conhecimento tácito não explicitado). As pessoas têm sido muito generosas em realmente querer compartilhar e prezam pela transparência, até pela cultura local. [...]

A pessoa tem que se sentir à vontade, acolhida. Por mais absurda que seja uma colocação, você tem que ter habilidade para sempre ter uma posição receptiva para que a pessoa se sinta à vontade. [...]

Após a análise de conteúdo, a partir da verificação das respostas dadas pelos nove gestores nas entrevistas, foi possível identificar e entender as relações existentes nas organizações pesquisadas, os conhecimentos tácitos e os compartilhamentos estabelecidos nas relações entre o indivíduo e sua respectiva organização.

Pode-se perceber com a pesquisa que os gestores realizam ações propostas no modelo desenvolvido por Lemos (2008) para a transferência de conhecimento tácito, provenientes dos quatro indicadores e vieses do modelo.

A busca de uma aproximação real com todos os colaboradores, com expedientes como circulação pelo "chão" de fábrica, porta aberta, simplicidade, informalidade, quebra de hierarquia, despojamento e transparência fazem uma grande diferença na energização da equipe de trabalho. Com conversas diretas e objetivas, onde os funcionários sentem-se próximos do dono, criando vínculos pessoais e profissionais, absorvendo melhor a cultura e os valores da empresa e, por conseguinte, aumentando o seu nível de comprometimento, interdependência e motivação para o desenvolvimento das competências da empresa. Com isto, obtém-se maior compartilhamento de conhecimento, redução da rotatividade de pessoal e se evita perda de conhecimento principalmente o tácito - para a concorrência.

Dono que é empresário e não mero administrador não cai na rotina. Crescimento e conforto não coexistem. O empresário busca desafios, tem a mente aberta e muda o tempo todo. Aceita desafios, mesmo quando acha que não vai conseguir fazer.

Quanto à gestão de sua equipe, o empresário adota uma postura receptiva que garante a liberdade e a abertura necessárias para que as pessoas se expressem. Ele sabe que o desempenho de sua organização depende essencialmente de seu pessoal, o qual deve ser eficiente, zeloso em suas funções e aplicado em seu desenvolvimento pessoal e profissional.

Uma forma de o empresário promover uma cultura de aprendizagem contínua a partir do conhecimento adquirido é colocar no mural principal da empresa, aquele ao lado do relógio-ponto, todos os seus dados para contato, como telefone (fixo e móvel), e-mail, face book, whatsapp, etc..

No subsequente contato pessoal, direto, presencial, de preferência em ambiente descontraído e somente a dois (colaborador e gestor), este último deve escutar, anotar e perguntar, nunca questionar, pôr dificuldades, bloquear a espontaneidade do funcionário e, muito menos, reprovar e descartar a aplicação do conhecimento oferecido. Passo seguinte, o dono deve prometer o 
encaminhamento do assunto, propor uma agenda e, o mais importante, uma resposta "face to face", tanto positiva como negativa ou intermediária (aquela com reformulações na aplicação da ideia, do conhecimento disponibilizado).

Uma percepção "periscópica", isto é, uma percepção integral em todas as direções, momentos, situações e relacionamentos, é outra forma de se extrair conhecimento tácito. Ler o que está por detrás e seguir seu instinto, olhando o ambiente, mas, também, para frente e longe, pois para acompanhar o mundo é preciso se reinventar continuamente.

Muito embora a pequena e média empresa não tenha uma lista enorme de metas e objetivos, ainda assim, o dono precisa ser flexível quanto a tudo que afeta sua empresa, pois a condições externas são muito voláteis.

Ademais, o gestor de um pequeno e médio negócio, limitado por sua condição financeira no mercado, tem que buscar produtividade, muito mais a partir de funcionários motivados, que produzem "mais com menos", do que por meio da compra de maquinários modernos. Afinal, mesmo com a extinção do emprego vitalício, a construção de relacionamentos fortes os torna mais duradouros, minimizando assim, a inexorável migração dos talentos humanos para as grandes empresas e a subsequente perda de conhecimento.

A caixa de sugestões, localizada num canto estratégico da empresa, também é outra forma de compartilhamento de conhecimento tácito, aplicada nas empresas. O investimento neste canal de comunicação, a caixa de sugestões, além de também aproximar a direção da base, demonstra a todos os funcionários, que eles, com ou sem identificação, estão convidados a pensar, sugerir e atuar no desenvolvimento e melhoria de processos, produtos e serviços da empresa, através de um processo gerencial e decisório o mais participativo possível. E que a empresa crê muito em sua equipe. Contudo, a maior dificuldade não está em captar as ideias dos funcionários, mas, sim, em criar um método para transformá-las em algo concreto. Muitas vezes, a ideia, o conhecimento e a competência se perdem, antes que sejam aplicadas, em alguma etapa da hierarquia, mesmo que enxuta.

Perto dos maiores problemas, estão as maiores oportunidades. Quando há uma crise ou uma situação "extrema", como em momentos de turbulência e stress causados, por exemplo, por problemas graves, complexos e aparentemente insolúveis em processos, máquinas ou produtos, as pessoas gastam muita energia em busca da solução. Evitando conflitos interpessoais, deixando de lado a busca de culpados, o que deve interessar, mesmo, é, sem dúvida, resolver o problema, prestando-se muita atenção ao conhecimento que aflora das pessoas, sob a forma de expressões autênticas, contribuições espontâneas, ideias, insights, feeling, competências desconhecidas e visão sistêmica "causa-efeito-solução". 
Não existe o inevitável e estes momentos "extremos" constituem terreno fértil para o compartilhamento e conhecimento, principalmente o tácito. Posturas passivas e comodistas do tipo “não dá", "não tem solução" e "não sei o que fazer", por exemplo, dão lugar à determinação, persistência e fé de que nada resiste ao trabalho sinergético, pois através dele as coisas acontecem.

Grande parte da captação do conhecimento pelas PMEs se dá por meio de feiras setoriais, visitas direcionadas, cursos de curta duração, palestras, catálogos de produtos e equipamentos e trocas de experiências com fornecedores, clientes e pares. Embora normalmente o dono ou o gestor mais próximo dele sejam os envolvidos, é cada vez mais comum que o envolvimento seja abrangente, coletivo, com o maior número possível de funcionários. É frequente, por exemplo, que sejam contratadas vans e até ônibus para que um grande número de funcionários visite feiras setoriais.

Assim, o compartilhamento do conhecimento se dá de maneira informal, em todas as direções, envolvendo pessoas de todos os níveis e funções, não numa reunião específica, num local pré-determinado ou com um determinado objetivo, mas numa interessante sinergia natural.

Encontros informais extraexpediente em associações recreativas, bares, pubs, restaurantes e festas familiares podem, também, contribuir para o compartilhamento do conhecimento profissional. A descontração, a informalidade, o contato com o "outro lado" do colega ou empregado, muitas vezes em volta de uma rodada descontraída, podem liberar alguns "freios psicológicos" que impedem uma pessoa, quando no ambiente e expediente de trabalho, de expressar suas ideias, seu conhecimento e sua competência.

Enfim, até mesmo os momentos de se jogar conversa fora podem ser apropriados - desde que usados alguns "filtros" - para o compartilhamento de conhecimento. Também o compartilhamento de hobbies, como pesca, bicicleta, jipe, parapentes e outros bem como o conhecido happy hour representam outras oportunidades informais de compartilhamento de conhecimento.

Embora sejam escassos, alguns instrumentos de gestão participativa nas pequenas e médias empresas, muito embora de natureza não tão sistemática e nem formal, a filosofia que norteia os Grupos de Controle de Qualidade, Grupos de Racionalização e Melhorias, Rodas Relâmpagos, Premiação e outros permeia grande parte das pequenas e médias empresas. Por outro lado, no que se refere à gestão do conhecimento, aqui entendida como o conjunto de ferramentas, métodos e técnicas que viabilizam a identificação, criação, estoque, disseminação e aplicação do conhecimento, as pequenas e médias empresas entrevistadas se utilizam do mesmo, embora de modo significativamente personalizado à sua cultura, realidade e situação financeira. 
É importante relatar, que por meio das entrevistas, pode-se evidenciar referências, também, à memória organizacional, benchmarking interno e externo, rotinas bem sucedidas e planejamento estratégico envolvendo seus colaboradores.

\section{Considerações Finais}

Mesmo com limitados recursos, de toda ordem, as PMEs precisam, principalmente, garantir a rentabilidade de seus negócios, adaptar a sua estrutura operacional e orgânica, desenvolver produtos e serviços de valor percebível, suportar financeiramente suas operações e projetos, adotar sistemas integrados e estratégicos de gestão, atrair, investir e reter talentos, gerir o conhecimento, promover a inovação e, ainda, alcançar custos e preços competitivos, fortalecendo a suas posições de mercado. Enfim, assegurar a sua sobrevivência e o seu crescimento (NORTH, DA SILVA NETO, DÁVILA CALLE, 2013).

No que se refere à gestão do conhecimento, as PMEs precisam criar condições para o compartilhamento do conhecimento, não só daquele acumulado e disseminado ao longo da sua existência organizacional, como também, e principalmente, daquele ainda implícito (tácito), de posse individual de seus integrantes, não explicitado, não compartilhado espontânea e horizontalmente com toda a equipe [NORTH, DA SILVA NETO, DÁVILA CALLE, 2013], afastando-se, assim, o perigo que ronda empresas de menor porte: como grande parte do conhecimento nestas organizações tende a ser tácito, informal e não registrado, dificultando, assim, a efetiva avaliação do seu know how, este pode ser facilmente fragmentado ou perdido quando do afastamento, por doença ou aposentadoria, do principal gestor, normalmente o próprio dono, ou quando ele vende o negócio (CEO, 2004).

Como o compartilhamento do conhecimento na pequena e média empresa é facilitado pela sua enxuta estrutura hierárquica, pouca burocracia em seus processos e sistemas e maior interação interpessoal entre a alta gerência (em grande parte, o próprio dono do negócio) e o nível operacional, ela precinde, geralmente, daqueles instrumentos sistemáticos formais das empresas maiores, como, por exemplo, CCQs, Grupos de Melhorias, Grupos de Racionalização e outros. Na realidade, a pequena e média empresa cria outras formas de compartilhamento e reutilização dos conhecimentos tácitos de seus funcionários que, se não melhores ou mais eficazes que os instrumentos formais, são, pelo menos, mais compatíveis ao porte e mais adequadas à simplicidade da empresa, possibilitando a identificação, a disseminação e a aplicação de importantes conhecimentos tácitos para a crescente capacitação da organização.

Nas PMEs, em relação às empresas de maior porte, é mais intensa a aproximação entre todos os colaboradores das PMEs, mediante circulação física por todos os cantos da empresa, portas 
abertas, simplicidade, informalidade, quebra de hierarquia, despojamento e transparência. A energização da equipe de trabalho ocorre com conversas diretas e objetivas, onde os funcionários sentem-se próximos do dono ou principal gestor, criando vínculos pessoais e profissionais, absorvendo melhor a cultura e os valores da empresa e, por conseguinte, aumentando o seu nível de comprometimento, interdependência e motivação para o desenvolvimento das competências da empresa. Com isto, obtém-se maior compartilhamento de conhecimento, redução da rotatividade de pessoal e se evita perda de conhecimento - principalmente o tácito - para a concorrência.

Os fatores, instrumentos e indicadores sociais relevantes para o sucesso no compartilhamento do conhecimento tácito, apresentados neste artigo, embora estudados especificamente para PMEs, podem ser utilizados nas empresas de maior porte, pois segundo Santos (2012), o conhecimento tácito é procedural, pessoal, específico de um determinado contexto e difícil de ser formulado e comunicado. Como envolve modelos mentais que estabelecem e manipulam analogias, a transmissão deste tipo de conhecimento se dá pela socialização, isto é, pela interação física, observação ou imitação.

\begin{abstract}
Small and medium-sized Brazilian companies, entered a highly competitive market, facing competitors of all sizes and nationalities, must always be attentive to the intrinsic characteristics of the segments in which they operate, in order to sustain or expand their competitive advantages [NORTH, DA SILVA NETO, DÁVILA CALLE, 2013]. For this, among many other skills, the entrepreneur must act with great vision, speed, flexibility and awareness in the management of its intellectual capital, aiming to overcome the challenges of the new society, the knowledge society, characterized by rapid and radical changes. With the intent to help him to facing these new challenges, this paper presents some forms of social interaction in small and medium enterprises, through stimulation, motivation and incentives, improving the sharing and reuse of tacit knowledge, making most employees feel useful and belonging to the company. A case study was conducted in 09 small and medium industries of Jaraguá do Sul, Santa Catarina state, city of strong economy and with one of the highest survival rates of companies in Brazil, which was evidenced relevant indicators for the success of sharing tacit knowledge in companies of this size.
\end{abstract}

Key-words: Knowledge Management; Tacit knowledge; SME's.

\title{
Referências
}

ABPT - Empresômetro - Censo das Empresas e Entidades Públicas e Privadas brasileiras. São Paulo: brprospect, 2012.

APO. Knowledge management: case studies for small and medium enterprises. Japan: APO, 2009.

CEO/COMITÉ EUROPÉEN DE NORMALISATION. European Guide to good Practice in Knowledge Management - Part 1: Knowledge Management Framework. Brussels: 2004.

DAVENPORT, T. H.; PRUSAK, P. Conhecimento empresarial: como as organizações gerenciam o seu capital intelectual. Rio de Janeiro: Elsevier, 2003. 
DELOITTE, T. T. As pequenas e médias empresas que mais crescem no Brasil: uma pesquisa sobre as rotas e estratégias que levam à expansão dos negócios. São Paulo: Exame PME, 2008.

DELOITTE, T.T. A receita da rentabilidade para expandir os negócios: um estudo sobre as PMEs que mais crescem no Brasil. São Paulo: Exame PME, 2011.

DISTERER, George. Fostering Knowledge Sharing: Why and How? In: REIS, Antonio, ISAIAS, Pedro (ed.). Proceedings of the IADIS International Conference e-Society 2003, Lisbon, 2003, p.219-226.

DOS SANTOS, N. Aula da disciplina Fundamentos de Gestão do Conhecimento. Florianópolis: EGC-UFSC, 2012.

DRUCKER, P. F. Inovação e espírito empreendedor (entrepreneurship): prática e princípios. São Paulo: Pioneira. 2001.

GIL, Antônio Carlos. Como elaborar projetos de pesquisa. São Paulo: Editora Atlas, 2002.

GIL, Antonio Carlos. Métodos e técnicas de pesquisa social. 6. ed. São Paulo: Atlas, 2008.

GLAZER, Rashi. Measuring the Knower: Towards a Theory of Knowledge Equity. California Management Review, v.40, n.3, Spring 1998, p.175-194. crossref

HANSEN, Morten; NOHRIA, Nitin; TIERNEY, Thomas. What's your Strategy for Managing Knowledge? Harvard Business Review, March-April, 1999, p.1-10.

HONORATO, Gilson. Conhecendo o marketing. Barueri, SP: Manole, 2004.

IBGE. Cidades. www.cidades.ibge.gov.br: 2010.

JAPIASSÚ, Hilton; MARCONDES, Danilo. Dicionário Básico de Filosofia. 4. ed. revista e ampliada, Rio de Janeiro: Jorge Zahar Editora, 2006.

JOIA, Luiz Antonio. Distributive Knowledge Transfer Processes in G2G Endeavours: A Heuristic Frame. In: TRAUNMÜLLER, R. (ed.) Knowledge Transfer for eGovernment: Seeking Better eGovernment Solutions. Trauner Verlag Universität, Linz, Austria, 2006, p.170-183.

JOIA, Luiz Antonio. Knowledge Management Strategies: Creating and Testing a Measurement Scale. International Journal of Learning and Intellectual Capital, 4(3), Inderscience, 2007, p.203-221.

LAKATOS, Eva Maria; MARCONI, Maria de Andrade. Fundamentos de Metodologia Científica. 5. ed. São Paulo: Atlas, 2009.

LAPOLLI, Juliana. Mapeamento de competências: uma Ferramenta para a gestão de pessoas utilizando a abordagem da teoria geral de sistemas. 2010.160 f. Dissertação (mestrado) - Programa de Pós-Graduação em Engenharia e Gestão do Conhecimento. Universidade Federal de Santa Catarina, Centro Tecnológico, Florianópolis. 
LEMOS, Bernardo Noronha. Fatores relevantes de sucesso à transferência do conhecimento tácito: evidências empírico-exploratórias em uma empresa petrolífera brasileira, 2008. 128 f. Dissertação (mestrado) - Fundação Getulio Vargas - FGV. Escola Brasileira de Administração Pública E De Empresas Centro de Formação Acadêmica e Pesquisa, Rio de Janeiro.

LEMOS, B.; JOIA, L. A. Fatores relevantes à transferência de conhecimento tácito em organizações: um estudo exploratório. Revista Gestão \& Produção, São Paulo, v. 19, n. 2, p. 233 246, 2012. crossref

LIN, H. F.; LEE, G. G. Effects of socio-technical factors on organizational intention to encourage knowledge sharing. Management Decision. Vol. 44 No. 1, 2006, p. 74-88. crossref

LI, M.; GAO, F. Why Nonaka highlights tacit knowledge: a critical review. Journal of Knowledge Management, 2003. crossref

MARRAS, P. J. Administração de recursos humanos: do Operacional ao Estratégico. 4. ed. São Paulo: Futura, 2001.

OECD. SDBS Business Demography Indicators

www.stats.oecd.org/Index.aspx?DataSetCode=SDBS_BDI, acesso em 14/06/2013.

NAHAPIET, J.; GHOSHAL, S. Social capital, intellectual capital, and the organizational advantage. Academy of Management Review, v. 23, n. 2, p.242-266, 1998.

NONAKA, I.; KONNO, N. The concept of Ba. California Management Review, 1998. crossref

NONAKA, Ikujiro; TAKEUCHI, Hirotaka. Criação de conhecimento na empresa: como as empresas japonesas geram a dinâmica da inovação. Rio de Janeiro: Campus, 1997.

NONAKA, I.; TAKEUCHI, H. Criação do conhecimento na empresa: como as empresas japonesas geram a dinâmica da inovação. Rio de Janeiro: Elsevier, 2004.

NONAKA, I.; TAKEUCHI, H. Teoria da criação do conhecimento organizacional. In: TAKEUCHI, H; NONAKA, I. Gestão do Conhecimento. Porto Alegre: Bookman, 2008, p.54-90.

NORTH, K. ; DA SILVA NETO, E. ; DÁVILA CALlE, G. Vencendo os desafios do crescimento: o método "aprender a crescer" para pequenas e médias empresas brasileiras. Navus - Revista de Gestão e Tecnologia, v. 3, 2013.

OECD. SDBS Business Demography Indicators

www.stats.oecd.org/Index.aspx?DataSetCode=SDBS_BDI, acesso em 14/06/2013.

O'DELL, C.; GRAYSON, C. J. "If only we knew what we know: identification and transfer of internal best practice', California Management Review, v. 40. n. 3, 1998, p. 154-74. crossref

POLANYI, M. The tacit dimension. London: Routledge \& Kegan Paul, 1966.

PORTAL BRASIL. Micro e pequenas empresas puxam crescimento do emprego desde 2010. Disponível em http://www.brasil.gov.br/noticias/arquivos/2011/12/2-1/micro-e-pequenas-empresaspuxam-crescimento-do-emprego-desde-2010.

PRAX, J. Y., Le Manuel du Knowledge Management. Paris: Polia Editions, 2005. 
REVISTA EMPREENDEDOR. Editorial. Florianópolis: Empreendedor, 2013.

ROESCH, S. M. A. Projetos de estágios do curso de administração: guia para pesquisas, projetos, estágios e trabalhos de conclusão do curso. São Paulo: Atlas, 1999.

SEBRAE. Serviço de Brasileiro de Apoio às Micro e Pequenas Empresas. Critérios e conceitos para classificação de empresas. 2012. Disponível em: <http://www.sebrae.com.br/uf/goias/indicadores-das-mpe/classificacao-empresarial>. Acesso em: 07 fev. 2012.

SEBRAE. Sobrevivência das empresas no Brasil. Brasília: UGE-Unidade de Gestão Estratégica, 2013.

SEBRAE SC. Santa Catarina em Números. Florianópolis: Sebrae SC, 2013.

SEVERINO, Antônio J. Educação, trabalho e cidadania: a educação brasileira e o desafio da formação humana no atual cenário histórico. São Paulo em Perspectiva, v.14, n.2, p. 65-71, 2000. Disponível em: < http://www.scielo.br/pdf/spp/v14n2/9790.pdf>. Acesso em: 28 jul. 2010.

STEWART, T. A. Capital Intelectual. 7. ed. Tradução de Ana Beatriz Rodrigues, Priscila Martins Celeste. Rio de Janeiro: Campus, 1998.

SZULANSKI, G. "Exploring internal stickiness: Impediments to the transfer of best practice within the firm," Strategic Management Journal, Vol 17: Special Issue, 1996, p. 27-43. crossref

TAKEUCHI, Hirotaka; NONAKA, Ikujiro. Gestão do conhecimento. Porto Alegre: Bookman, 2008.

TASSIGNY, Mônica Mota; BRASIL, Marcus Vinicius de Oliveira; BUGARIM, Maria Clara; NOGUEIRA, Fábio Luiz Benício Maia. Blog: ferramenta estratégica de comunicação organizacional. Rev. Adm. UFSM, Santa Maria, v. 5, n. 2, p. 262-276, MAI./AGO. 2012.

TAYLOR, S. J.; BOGDAN, R. Introduction to qualitative research methods: a guidebook and resource. 3. Ed. New York: John Wiley, 1997.

TRIVIÑOS, Augusto Nibaldo Silva. Introdução à Pesquisa em Ciências Sociais: a pesquisa qualitativa em educação. São Paulo: Atlas, 2007.

TRIVIÑOS, A. Introdução à pesquisa em ciências sociais: a pesquisa qualitativa em educação. São Paulo: Atlas, 2008.

VYGOTSKY, L. S. A Formação Social da Mente. São Paulo: Martins Fontes, 2007.

\section{Dados dos autores}

Nome completo: Emílio Da Silva Neto

Filiação institucional: Arco-Íris Alimentos Ltda e Doutorando em Engenharia e Gestão do Conhecimento EGC-UFSC 
Departamento:

Função ou cargo ocupado: Sócio-Diretor Comercial e Industrial

Endereço completo para correspondência: Rua João Januário Ayroso, 2555 ? Jaraguá Esquerdo /

Jaraguá do Sul-SC. CEP 89.253-100

Telefones para contato: 4799779595 e 33708255

e-mail: emilio@arcoirisalimentos.com.br

Nome completo: Inara Antunes Vieira Willerding

Filiação institucional: Faculdade Energia de Administração e Negócio - FEAN e Doutoranda em

Engenharia e Gestão do Conhecimento - EGC-UFSC

Departamento:

Função ou cargo ocupado: Docente

Endereço completo para correspondência: Rua Vereador Osni Ortiga, 2037, apto. 21 - Lagoa da

Conceição / Florianópolis-SC. CEP 88.062-451

Telefones para contato: (48) 9962-1744

e-mail: inara.antunes@gmail.com

Nome completo: Neri dos Santos

Filiação institucional: Pró-Reitor de Pós-Graduação, Pesquisa e Extensão

Centro Universitário Internacional - UNINTER

Departamento: Campus DIVINA

Função ou cargo ocupado: Pró-Reitor de Pós-Graduação, Pesquisa e Extensão Centro Universitário Internacional - UNINTER

Endereço completo para correspondência: Rua do Rosário, 147 - Centro / Curitiba-PR. CEP 80.020010

Telefones para contato: (41) 21024995

e-mail:neri.s@uninter.com

Nome completo: Édis Mafra Lapolli

Filiação institucional: Universidade Federal de Santa Catarina ? UFSC

Departamento: Programa de Pós-Graduação em Engenharia e Gestão do Conhecimento - PPGEGC

Função ou cargo ocupado: Docência

Endereço completo para correspondência: Rua Duarte Schutel, 100, apto. 502 - Centro -

Florianópolis-SC. CEP 88.015-640

Telefones para contato: (48) 9982-5258 
e-mail:edispandion@gmail.com

Submissão: 2014-11-12

Aceito em: 2015-05-07 